\title{
COMMUTATORS, PINCHINGS, AND SPECTRAL VARIATION
}

\author{
RAJENDRA BHATIA AND FUAD KITTANEH
}

Abstract. The three topics of the title have been studied by several authors. The main aim of this note is to point out interesting connections between them.

Mathematics subject classification (2000): 15A42, 15A60, 47A30, 47B47.

Key words and phrases: Commutator, pinching, spectral variation, inequality.

\section{REFERENCES}

[1] R. Bhatia, Matrix Analysis, Springer-Verlag, New York, 1997.

[2] R. Bhatia, Perturbation Bounds for Matrix Eigenvalues, Classics in Applied Mathematics, 53, SIAM, Philadelphia, 2007.

[3] R. Bhatia, Positive Definite Matrices, Princeton University Press, Princeton, 2007.

[4] R. BHATIA, M.-D. CHOI, AND C. DAVIs, Comparing a matrix to its off-diagonal part, Oper. Theory Adv. Appl. 40 (1989), 151-164.

5] R. Bhatia AND F. KitTANEH, On the singular values of a product of operators, SIAM J. Matrix Anal. Appl. 11 (1990), 272-277.

[6] A. BÖTTCHER AND D. WenZEL, How big can the commutator of two matrices be and how big is it typically? Linear Algebra Appl. 403 (2005), 216-228.

[7] F. KitTANEH, Norm inequalities for commutators of positive operators and applications, Math. Z., in press.

[8] F. KitTANEH, Inequalities for commutators of positive operators, J. Funct. Anal. 250 (2007), 132-143.

[9] L. LÁsZLó, Proof of Böttcher and Wenzel's conjecture on commutator norms for 3-by-3 matrices, Linear Algebra Appl. 422 (2007), 659-663.

[10] J.G. STAMPFL, The norm of a derivation, Pacific J. Math. 33 (1970), 737-747.

[11] S.-K. Vong AND X.-Q. JIN, Proof of Böttcher and Wenzel's conjucture, Oper. Matrices, in press.

[12] Y.-Q. WANG AND H.-K. DU, Norms of commutators of self-adjoint operators, J. Math. Anal. Appl., in press.

[13] X. ZHAN, On some matrix inequalities, Linear Algebra Appl. 376 (2004), 299-303. 